\title{
Threshold Vegetation Greenness under Water Balance in Different Desert Areas over the Silk Road Economic Belt
}

\author{
Yu-Jun Ma ${ }^{1,2,3, *(\mathbb{D}}$, Fang-Zhong Shi ${ }^{3}$, Xia Hu ${ }^{2,3}$ and Xiao-Yan $\mathrm{Li}^{2,3,4}$ \\ 1 School of Geography and Planning, Sun Yat-sen University, Guangzhou 510275, China \\ 2 State Key Laboratory of Earth Surface Processes and Resource Ecology, Faculty of Geographical Science, \\ Beijing Normal University, Beijing 100875, China; huxia@bnu.edu.cn (X.H.); xyli@bnu.edu.cn (X.-Y.L.) \\ 3 School of Natural Resources, Faculty of Geographical Science, Beijing Normal University, \\ Beijing 100875, China; fzshi@mail.bnu.edu.cn \\ 4 Key Laboratory of Tibetan Plateau Land Surface Processes and Ecological Conservation, \\ Ministry of Education, Qinghai Normal University, Xining 810016, China \\ * Correspondence: mayujun3@mail.sysu.edu.cn
}

Received: 28 June 2020; Accepted: 29 July 2020; Published: 30 July 2020

\begin{abstract}
The sustainability of dryland vegetation growth over the Silk Road Economic Belt is under threat of water shortage, and the determination of water carrying capacity for vegetation is critically essential to balance water supply and water demand for the maintenance of existing ecosystems. To better understand how and why vegetation growth varies in different desert areas, this study first analyzed the spatiotemporal variation of the normalized difference vegetation index (NDVI). Then, we investigated the relationship between NDVI and climatic factors (precipitation, soil water content, air temperature, evapotranspiration), and estimated the threshold NDVI under water balance in different desert areas. Results showed that the higher NDVI was mainly distributed in Kazakhstan, Russia, and Azerbaijan, and it increased in approximately 53\% of desert areas from 1982 to 2015 in the whole study region. The mean annual NDVI showed a simultaneous increasing trend in all desert areas from 1982 to 1994, and decreased significantly only in the cold arid desert area $(p<0.01,-0.0067$ decade $\left.^{-1}\right)$ or had no significant change in other desert areas after $1994(p>0.01)$. The climate condition generally appeared as a warming and drying trend in the past 34 years, with varied changing rates in different desert areas. NDVI presented a strong positive relationship with both precipitation and evapotranspiration in most desert areas. The threshold values of the mean annual NDVI under water balance between 1982 and 2015 were approximately 0.1041 (hot arid desert), 0.1337 (cold arid desert), 0.1346 (cold arid semi-desert), 0.0951 (hot arid desert semi-desert), 0.0776 (polar desert tundra), 0.1071 (hot arid desert shrub), 0.1377 (cold arid desert steppe), and 0.0701 (polar desert steppe), respectively. The responses of these threshold values to precipitation were all positive in different desert areas. These results provide an enhanced understanding of vegetation dynamics and ecological conservation, which are of great importance to implementing adaptation and mitigation measures for terrestrial ecosystems over the Silk Road Economic Belt.
\end{abstract}

Keywords: precipitation; evapotranspiration; NDVI; desert area; Silk Road Economic Belt

\section{Introduction}

The Silk Road Economic Belt was proposed by the Chinese government in 2013, and aims to promote the development of an open world economic system by strengthening interregional cooperation [1]. It links China with central Asia, west Asia, southeast Asia, south Asia, Russia, and Europe [2], and contains lots of desert over the world, such as Arabian desert, Taklimakan 
desert, and Kazakh semi-desert. Characterized by a dry climate, vegetation over the Silk Road Economic Belt is highly sensitive to climate change and human activities over multiple timescales [3]. Previous studies declared that precipitation in central Asia exhibited great spatial heterogeneity and multi-decadal variations over the last century, with a sharp decline during 1901-1944, followed by an increase until the 1980s, and a fluctuation thereafter [4,5]. The rising temperature exacerbated water stress by increasing the surface evapotranspiration and stimulating substantial glacial retreats [6-8]. Overgrazing and other unsustainable anthropogenic activities further aggravated the degradation of existing vegetation $[9,10]$. Moreover, different desert areas presented varied climatic characteristics [5,11]. Generally, the sustainability of dryland vegetation growth in different desert areas over the Silk Road Economic Belt is under threat of dramatic environmental change [12,13].

Water is the most important limiting factor for vegetation growth in dryland regions $[14,15]$. Precipitation determines how much water is available for vegetation, while evapotranspiration determines how much water will be consumed by vegetation. As a consequence, they codetermine the long-term water budget in arid and semi-arid areas. On the one hand, previous studies revealed that any trend in the normalized difference vegetation index (NDVI) may reflect variation in the precipitation amount over time. For example, the contemporary greening patterns in the Sahel were mainly driven by increased rainfall [16], and vegetation development is sensitive to precipitation anomalies for nearly $80 \%$ of the central Asian land surface [17]. Moreover, diverse vegetation presented a varied response to precipitation anomalies under different climatic and biogeographical conditions $[3,18,19]$. On the other hand, $\mathrm{Xu}$ et al. found that annual reference evapotranspiration and actual evapotranspiration showed a significant opposite trend during the period 1960-2014 over the upper reaches of the Yellow River Basin, and large-scale coherent vegetation greening is the primary factor leading to a dramatic increase in actual evapotranspiration [20]. Modelling results by the Budyko framework also demonstrated significant positive relationships between evapotranspiration and vegetation coverage on both an annual scale and long-term scale (30-year period) [21]. In addition, distinguishing vegetation types also produced different effects on remotely sensed evapotranspiration in arid regions [22]. Therefore, the determination of vegetation density is critically essential to balance water supply (precipitation) and water demand (evapotranspiration) for the long-term maintenance of existing ecosystems in arid and semi-arid regions.

The water carrying capacity for vegetation can be defined as the maximum density (or coverage, biomass, greenness, and so on) of a given type vegetation, under specific climatic conditions, soil texture, and management regime, that an arid or semi-arid area can sustain without diminishing the soil water to support future generations [23-25]. It is a useful concept for theoretical analysis, but it is extremely difficult for practical applications, due to the multiscale variability of vegetation and environmental conditions. Empirical methods for estimation of the water carrying capacity for vegetation requires many field experiments and site-specific properties [26,27]. Conceptual models cannot account for the dynamic interactions between water and vegetation for heterogeneous environmental matrices [28]. Physical models have been developed for the estimation of water carrying capacity for vegetation; however, too many initial parameters or only a one-dimensional modelling ability limited their utilization at a large spatial scale [24,29]. Therefore, at the regional scale, a statistical model based on the vegetation index and environmental factors using remote sensing datasets may be one useful pathway to determine the water carrying capacity for vegetation [30].

Overall, it is necessary to monitor vegetation growth over the Silk Road Economic Belt and explore its relationship with climate change to ensure sustainable eco-environmental protection and socioeconomic development. However, the water carrying capacity for vegetation in this dryland has not been studied in detail. Two fundamental questions remain: (i) How does the vegetation growth and corresponding climatic factors vary and interact with each other in different desert areas? (ii) What is the threshold value of vegetation greenness under water balance and its response to precipitation change? The objective of this study, therefore, was to identify the spatiotemporal pattern of vegetation 
dynamics, and quantitatively determine its control by climatic factors and threshold NDVI under water balance in different desert areas over the Silk Road Economic Belt.

\section{Materials and Methods}

\subsection{Study Region}

The study region located in the Silk Road Economic Belt (https://en.tianditu.gov.cn/, "Layers"_"Silk Road"-“Land and Sea Silk Road"), which includes lots of desert areas (the area associated with desert ecosystem) in the northwest China, central Asia, Arabian Peninsula, and parts of North Africa. The desert areas were generated from a map of the global ecoregions, which was first produced by the World Wildlife Fund (https://www.worldwildlife.org/biomes) and further visualized by National Earth System Science Data Centre of China (http://www.geodata.cn/data/datadetails.html?dataguid=208109344688128\&docId= 19421, in Chinese). The desert areas over the Silk Road Economic Belt included six desert ecosystems: Desert, semi-desert, desert semi-desert, desert tundra, desert-shrub, and desert steppe. According to the world maps of the Köppen-Geiger climate classification (http://koeppen-geiger.vu-wien.ac.at/shifts.htm), the main climates in these desert areas included hot arid, cold arid, and polar. The mean annual precipitation and air temperature were $157 \mathrm{~mm}$ and $14.81^{\circ} \mathrm{C}$ between 1982 and 2015 in the whole study region, respectively. Based on the global ecoregions and climate classification, the study region was separated into eight subregions, including hot arid desert (HAdese), cold arid desert (CAdese), cold arid semi-desert (CAsmde), hot arid desert semi-desert (HAdesm), polar desert tundra (POdetu), hot arid desert shrub (HAdesh), cold arid desert steppe (CAdest), and polar desert steppe (POdest) (Figure 1). Their areas accounted for 20.5\%, 22.0\%, 21.3\%, 9.0\%, 1.1\%, 16.6\%, 6.1\%, and 3.4\% of the whole study region, respectively. The hot arid desert shrub area and hot arid desert semi-desert area were concentrated on the Arabian Peninsula and southwest Iran; the polar desert tundra only appeared in the border area of Tajikistan, Kyrgyzstan, and China; while the desert area, semi-desert area, and desert steppe area were distributed widely in the whole study region.

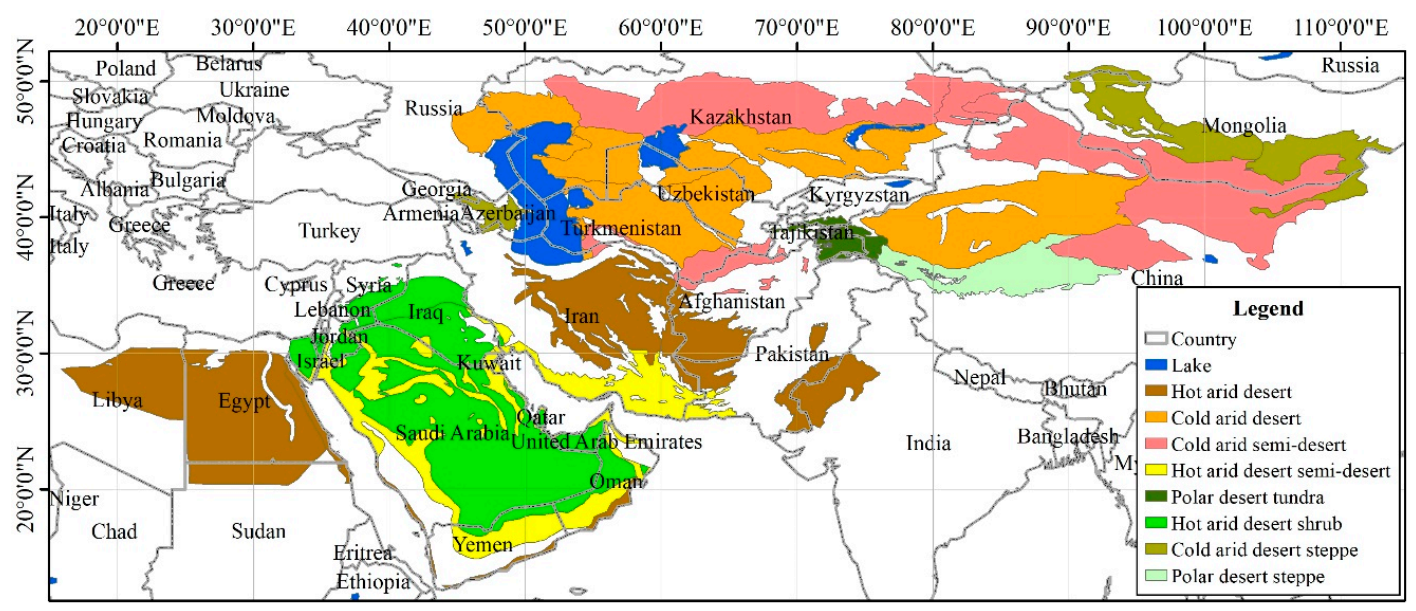

Figure 1. Location of different desert areas over the Silk Road Economic Belt.

\subsection{Datasets}

The vegetation growth between 1982 and 2015 was evaluated by the normalized difference vegetation index (NDVI), derived from the Advanced Very High Resolution Radiometer (AVHRR) observations produced by the Global Inventory Modeling and Mapping Studies (GIMMS) group (i.e., GIMMS NDVI3g v1, https://ecocast.arc.nasa.gov/data/pub/gimms/), with a spatial resolution of 1/12 degrees $(8 \mathrm{~km})$ and biweekly temporal resolution (two images in each month). It has been comprehensively corrected for atmospheric effects, sensor degradation, solar zenith angle, cloud contamination, and inter-sensor differences [31], and widely used to investigate spatiotemporal patterns in vegetation growth across 
diverse bioclimatic regions [32,33]. To match the climate grid data, the raw NDVI data was resampled to a spatial resolution of 0.25 degrees and monthly temporal resolution. For spatially resampling, we averaged the data of nine grids with three rows and three columns to resample the $1 / 12$ degrees to 0.25 degrees. For temporal resampling, we averaged the data of two images in each month to get the monthly dataset. Due to the different lengths of the growing season in the widespread region over the Silk Road Economic Belt [34], the mean annual NDVI was used in this study.

The monthly gridded air temperature (TEM), precipitation (PRE), and soil water content (SWC) with a spatial resolution of 0.25 degrees in period of 1982-2015 were obtained from the ERA5 (ECMWF Re-Analysis) dataset produced by European Centre for Medium-Range Weather Forecasts (ECMWF, https://cds.climate.copernicus.eu/cdsapp\#!/dataset/reanalysis-era5-single-levels-monthlymeans?tab=overview). The soil water content in four layers was averaged to cover the region from surface to the root region with a depth of $2.89 \mathrm{~m}$ (https://confluence.ecmwf.int/display/CKB/ERA5\%3A+ data+documentation). Compared with ERA-Interim, the biases in ERA5 have been greatly reduced [35].

The monthly gridded evapotranspiration (ET) with a spatial resolution of 0.25 degrees between 1982 and 2015 was obtained from the Global Land Evaporation Amsterdam Model (GLEAM, https: //www.gleam.eu/). GLEAM first calculates potential evaporation using the Priestley and Taylor equation based on observations of surface net radiation and near-surface air temperature, and further converted into actual evaporation using a multiplicative evaporative stress factor based on observations of microwave vegetation optical depth and estimates of root-zone soil moisture [36,37].

\subsection{Data Analysis}

Based on the PRE, ET, and SWC, the water balance equation for different desert areas can be expressed as follows:

$$
\begin{gathered}
R=P R E_{t}-E T-\sum_{i}^{n}\left(\Delta S W C_{i} * D_{i}\right), \\
a=\frac{R}{P R E_{t}}, \\
P R E_{a}=P R E_{t} *(1-a),
\end{gathered}
$$

where $R$ is the runoff, and is calculated by the water balance method (Equation (1)); $a$ is the runoff coefficient; $P R E_{t}$ and $P R E_{a}$ are the total and available precipitation, respectively; and $\triangle S W C_{i}$ and $D_{i}$ are the soil water content change and thickness in the $i$ layer, respectively.

According to the preliminary investigation of the raw data, we found one obvious turning point (i.e., the change rate before and after which has the maximum difference) of the mean annual NDVI. Therefore, two piecewise linear regression models were applied to assess the change trends of the mean annual NDVI, precipitation, soil water content, air temperature, and evapotranspiration in different desert areas, and the change rates were quantified by the slopes of the linear regressions [38].

Structural equation modeling is a statistical methodology that takes a confirmatory (i.e., hypothesis testing) approach to the analysis of a structural theory bearing on some phenomenon. It conveys two important aspects of the procedure: (a) The causal processes under study are represented by a series of structural (i.e., regression) equations, and (b) these structural relations can be modeled pictorially to enable a clearer conceptualization of the theory under study [39]. It has been widely used to visualize causal processes and quantify the influence degree of direct and indirect effects [40]. We used it to quantify the effect of climatic factors on NDVI in different desert areas, and the overall test of the model fit (chi-square), as well as tests of individual parameters ( $p$ value), were utilized to estimate the performance of the model. Structural equation model analyses were conducted using Amos 24 (IBM SPSS, http://www.spss.com.hk/amos/) [41].

Threshold NDVI was defined as "the NDVI under water balance, i.e., water supply (available precipitation) equals to water demand (evapotranspiration) for natural vegetation". For the calculation of this threshold value, single linear regression was first used to analyze the correlation 
between mean annual available precipitation and NDVI, and between mean annual evapotranspiration and NDVI, respectively. Then, the NDVI corresponding to the intersection of these two linear regressions was taken as the threshold NDVI.

\section{Results}

\subsection{Spatiotemporal Variation of NDVI}

The mean annual NDVI between 1982 and 2015 in all desert areas over the Silk Road Economic Belt ranged from 0.0001 to 0.6361 (Figure 2a). It generally increased with the increase of latitude, i.e., the higher NDVI was mainly distributed in Kazakhstan, Russia, and Azerbaijan, with the lower values in North Africa, Arabian Peninsula, Iran, and northwest China. From 1982 to 2015, NDVI increased in approximately $53 \%$ of the desert areas and decreased in the other $47 \%$ of the desert areas, with an average change of 0.0007 in the whole study region (Figure $2 \mathrm{~b}$ ). The greening region accounted for $57 \%, 39 \%, 60 \%, 53 \%, 59 \%, 47 \%, 60 \%$, and $81 \%$ of the area in the hot arid desert, cold arid desert, cold arid semi-desert, hot arid desert semi-desert, polar desert tundra, hot arid desert shrub, cold arid desert steppe, and polar desert steppe area, respectively. The regions of large increases in NDVI were distributed in the middle and east of Kazakhstan, the northwest of China, while the decreasing regions were mainly distributed around the Aral Sea and on the north of Caspian Sea. In other words, the pronounced change of mean annual NDVI was also concentrated on the high-latitude regions.
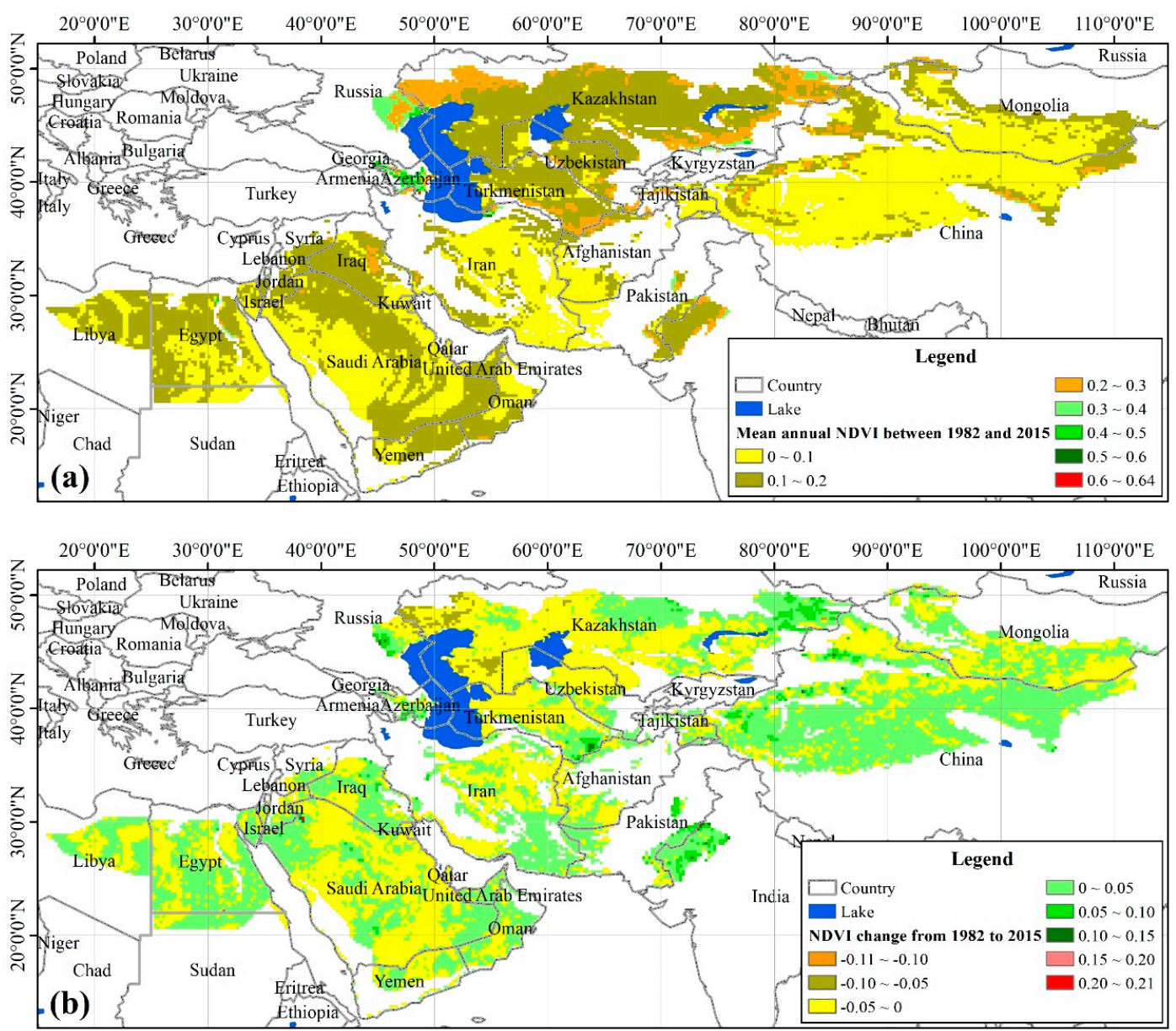

Figure 2. Mean annual NDVI (normalized difference vegetation index, (a) and its change range $\left(\mathrm{NDVI}_{2015}-\mathrm{NDVI}_{1982}\right.$, (b) in desert areas over the Silk Road Economic Belt between 1982 and 2015. 
An obvious turning point of the mean annual NDVI in desert areas over the Silk Road Economic Belt was found around 1994 (Figure 3). NDVI showed a simultaneous increasing trend from 1982 to 1994 in all desert areas, with the maximum rising rate of 0.0108 decade $^{-1}$ in the cold arid desert steppe area. However, NDVI decreased significantly in the cold arid desert area with an average reduction rate -0.0067 decade $^{-1}(p<0.01)$, or had no significant change trend in other desert areas $(p>0.01)$ after 1994. Therefore, vegetation greening appeared in all desert areas between 1982 and 1994, while extensive vegetation browning mainly happened in the cold arid desert area after 1994.
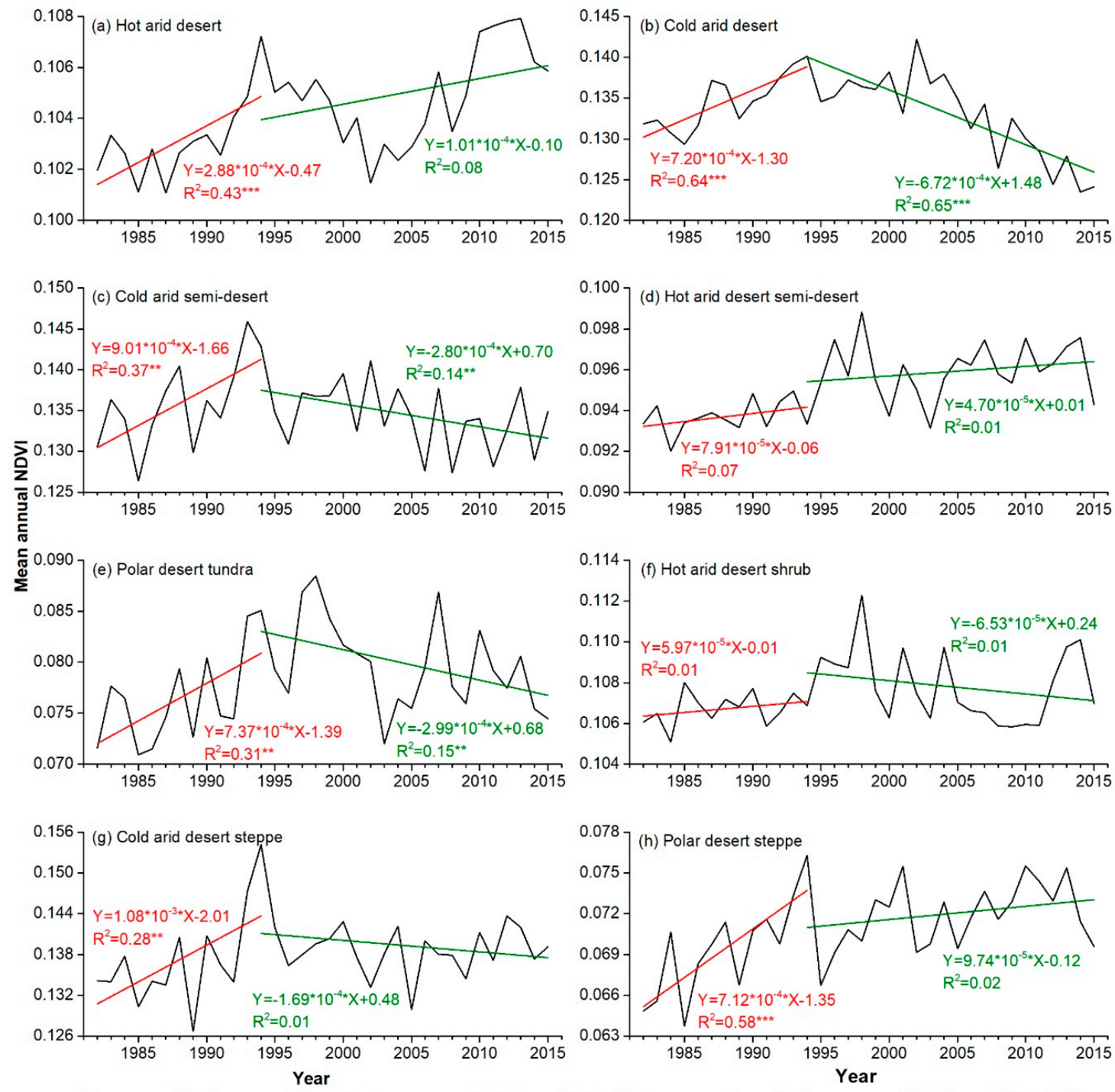

- Mean annual NDV

_Linear fit of mean annual NDVI from 1982 to 1994

_Linear fit of mean annual NDVI from 1994 to 2015

Figure 3. Interannual change of mean annual NDVI in different desert areas over the Silk Road Economic Belt from 1982 to $2015 .{ }^{* *}$ and ${ }^{* * *}$ indicate statistical significance at $p<0.05$ and $p<0.01$, respectively.

\subsection{Effect of Climatic Factors on NDVI}

Four climatic factors in desert areas over the Silk Road Economic Belt presented marked variation patterns from 1982 to 2015 (Figure 4). The mean annual precipitation was higher than $600 \mathrm{~mm}$ in the polar desert tundra area, and less than $100 \mathrm{~mm}$ in all hot arid areas (desert, desert semi-desert, and desert shrub). Precipitation generally decreased in the past 34 years for most of the desert areas, especially in the cold arid desert steppe area, with an average decreasing trend of $2.79 \mathrm{~mm} \mathrm{yr}^{-1} \mathrm{between}$ 1994 and 2015. In accordance with precipitation, the mean annual soil water content was higher than $0.2 \mathrm{~m}^{3} / \mathrm{m}^{3}$ in the polar areas (desert tundra and desert steppe), between 0.1 and $0.2 \mathrm{~m}^{3} / \mathrm{m}^{3}$ in all cold 
arid areas (desert, semi-desert, and desert steppe), and lower than $0.1 \mathrm{~m}^{3} / \mathrm{m}^{3}$ in all hot arid areas. Soil water content decreased in all desert areas after 1994, especially in all cold arid areas, hot arid desert area, hot arid desert shrub area, and polar desert tundra area, with a significant downtrend $(P<0.01)$. The mean annual air temperature differs greatly between diverse desert areas, and the highest and lowest values distributed in the hot arid desert semi-desert area and the polar desert steppe area, respectively. Air temperature showed an increasing trend in all desert areas from 1994 to 2015 , and the rising rate reached $0.036{ }^{\circ} \mathrm{C} \mathrm{yr}^{-1}$ or larger in all hot arid areas. The mean annual evapotranspiration had the highest value in the cold arid desert steppe area, and the lowest value in the hot arid desert shrub area. It increased in all desert areas between 1994 and 2015, with a significant increasing rate $1.93 \mathrm{~mm} \mathrm{yr}^{-1}$ in the cold arid desert steppe area $(P<0.01)$.
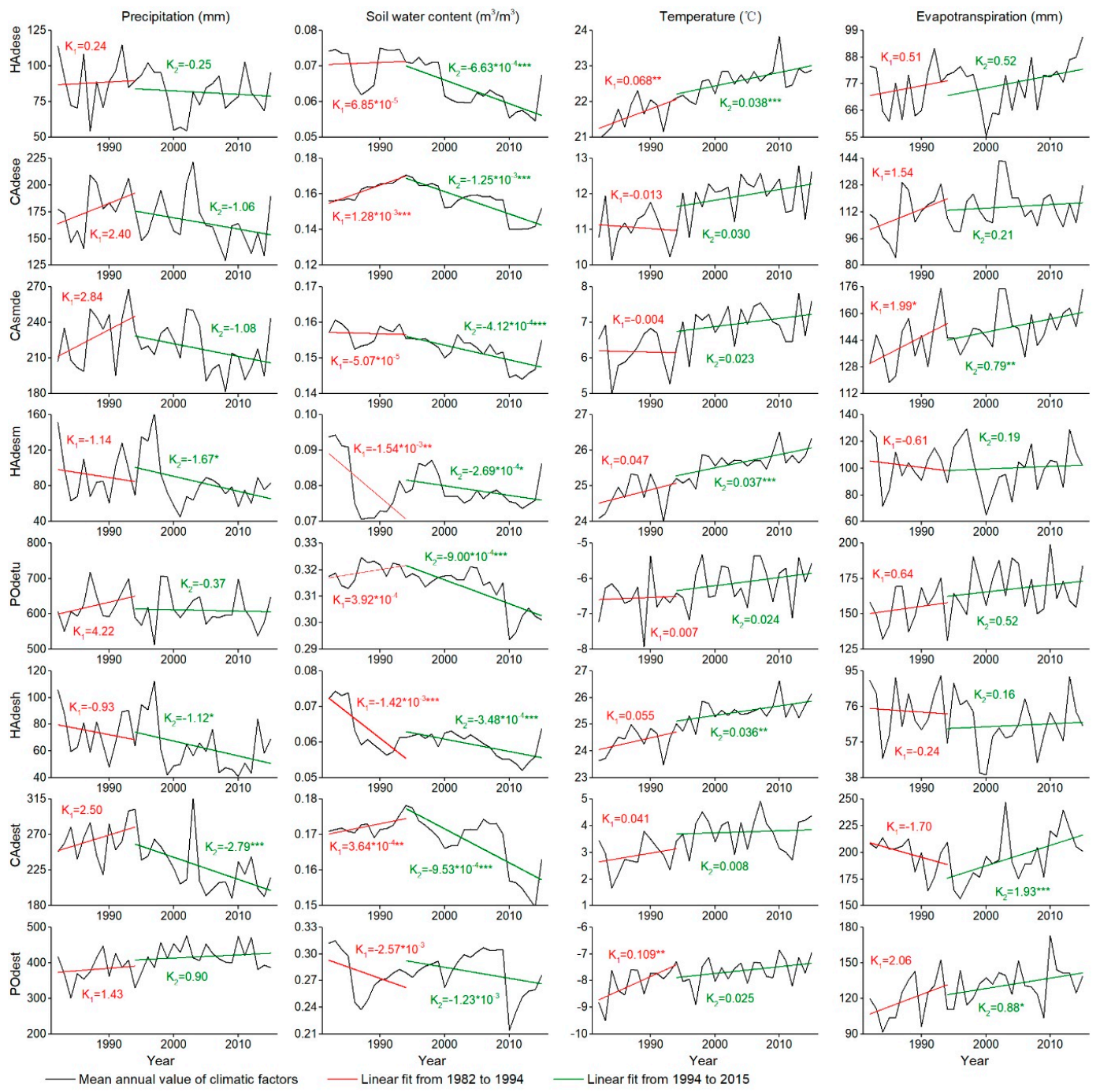

Figure 4. Interannual change of the mean annual value of climatic factors in different desert areas over the Silk Road Economic Belt from 1982 to $2015 . K_{1}$ and $K_{2}$ are the slope of the linear regression from 1982 to 1994 and from 1994 to 2015, respectively. ${ }^{*}, * *$ and ${ }^{* * *}$ indicate statistical significance at $p<0.1, p<0.05$, and $p<0.01$, respectively. HAdese-hot arid desert, CAdese-cold arid desert, CAsmde — cold arid semi-desert, HAdesm—-hot arid desert semi-desert, POdetu—polar desert tundra, HAdesh—hot arid desert shrub, CAdest—cold arid desert steppe, POdest—polar desert steppe.

The structural equation model indicated complicated interactions between climatic factors and NDVI in different desert areas over the Silk Road Economic Belt (Figure 5). Precipitation showed a significant positive effect on NDVI in all hot arid and cold arid areas $(p<0.01)$. In contrast, the influence 
of air temperature on NDVI was not significant in all cold arid areas $(p>0.01)$. Moreover, air temperature also showed a significant negative influence on evapotranspiration in the hot arid desert semi-desert area, hot arid desert shrub area, and cold arid desert steppe area $(p<0.01)$, indicating that temperature conditions may not be the limiting factors on vegetation growth and hydrological processes in these regions. NDVI presented a positive relationship with evapotranspiration in all desert areas, and this effect was significant in the hot arid desert area, cold arid desert area, cold arid semi-desert area, and hot arid desert semi-desert area $(p<0.01)$. Overall, one key action path might be that precipitation affected NDVI first and evapotranspiration further. Standardized total effects also certificated these interactions between water conditions (precipitation, soil water content), temperature condition, evapotranspiration, and NDVI. On the one hand, precipitation was the most important influencing factor on NDVI in all cold arid areas. On the other hand, NDVI showed a remarkably strong positive relationship with evapotranspiration in most desert areas. Generally, vegetation variation in desert areas was controlled by the water balance between precipitation and evapotranspiration.
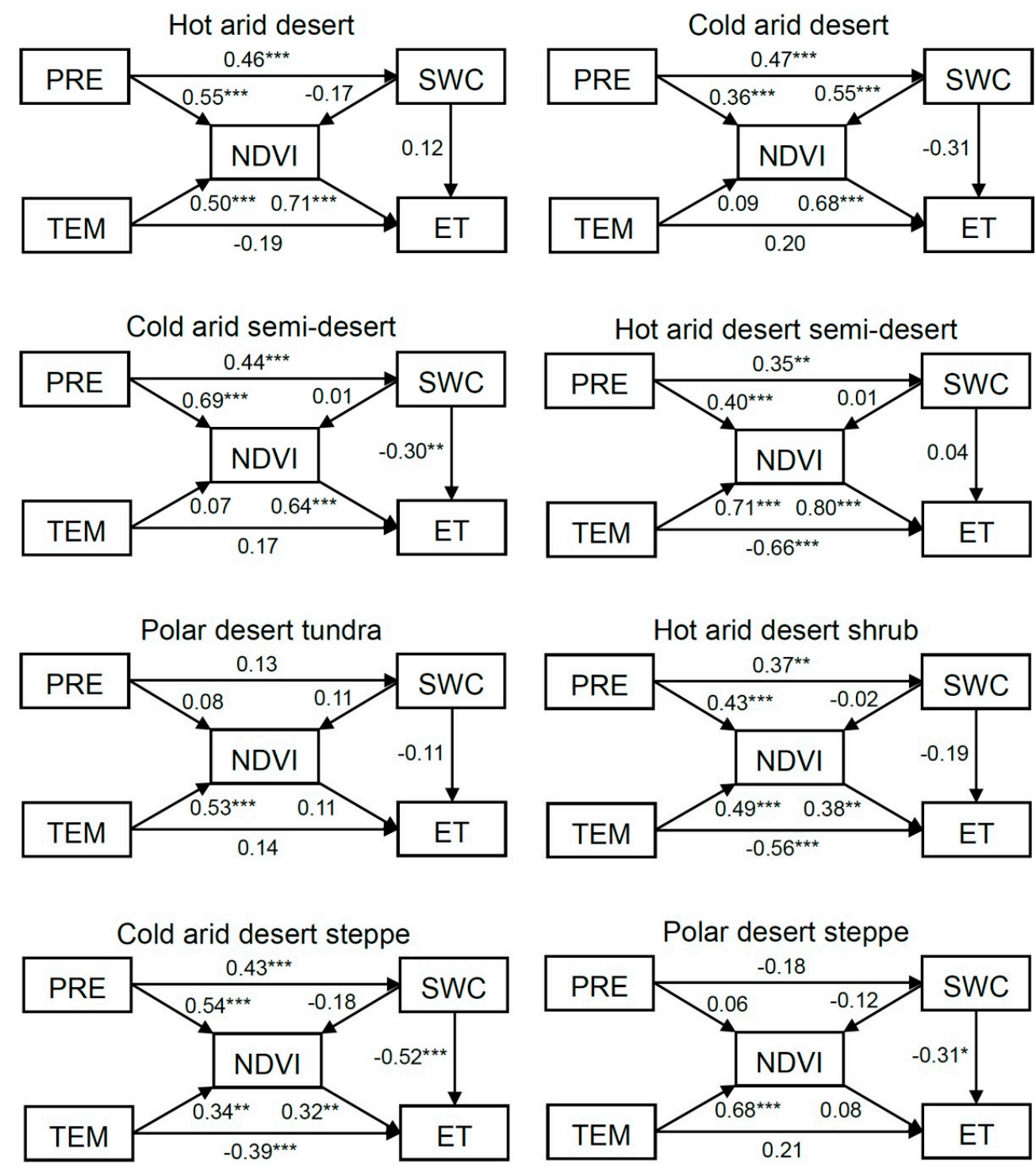

Figure 5. Structural equation model of the mean annual NDVI and climatic factors in different desert areas over the Silk Road Economic Belt between 1982 and 2015. ***, and *** indicate statistical significance at $p<0.1, p<0.05$, and $p<0.01$, respectively. PRE-Precipitation, SWC-Soil water content, ET-Evapotranspiration, TEM-Air temperature. 


\subsection{Threshold NDVI under Water Balance}

Both mean annual available precipitation and mean annual evapotranspiration showed a significant positive correlation with mean annual NDVI $(p<0.01)$, and the slope of the former one was smaller than the latter one (Figure 6). The mean annual NDVI corresponding to the intersection point of these two fit lines was 0.1174. As the standard deviation of the mean annual NDVI between 1982 and 2015 was 0.0021 , we infer that the threshold range of the mean annual NDVI under water balance in all desert areas over the Silk Road Economic Belt may be 0.1153 0.1195.

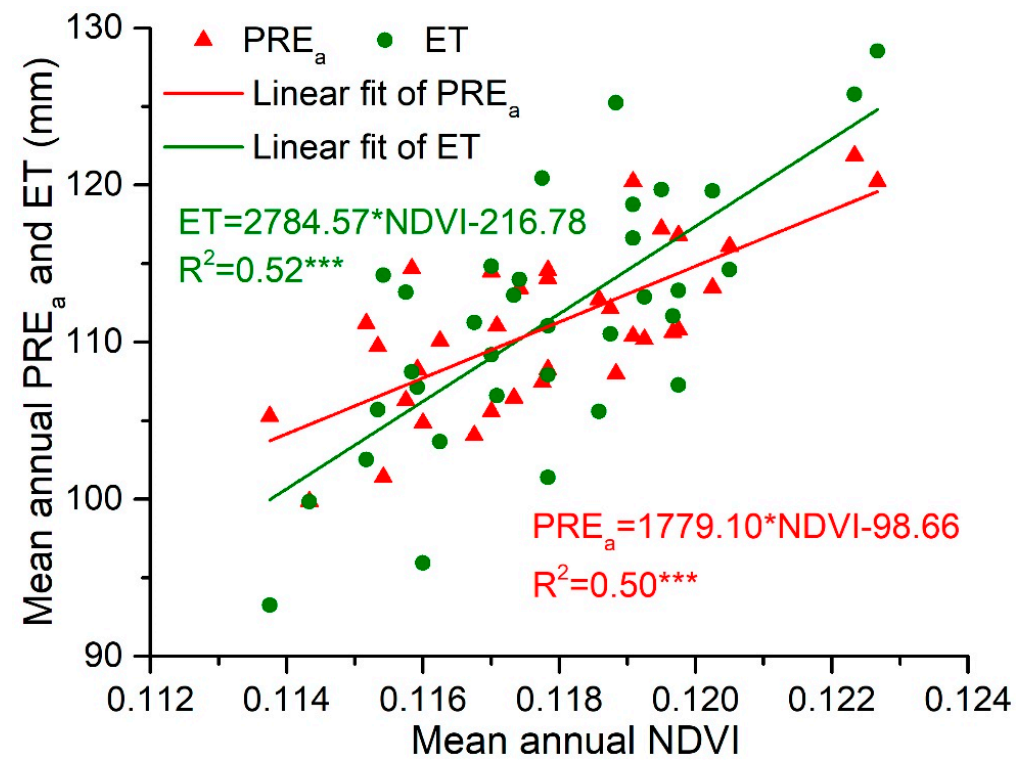

Figure 6. The correlation between mean annual available precipitation, mean annual evapotranspiration, and mean annual NDVI in all desert areas over the Silk Road Economic Belt between 1982 and 2015.

*** indicates statistical significance at $p<0.01$. PRE - Available precipitation, ET-Evapotranspiration.

For the different desert areas, the threshold NDVI and its variation with precipitation change was obviously diverse (Figure 7, Table 1). The threshold value of the mean annual NDVI was generally higher in cold arid areas, followed by hot arid areas, and very low in polar areas. The response of the mean annual NDVI to precipitation was all positive in different desert areas, and generally represented the same order as the threshold NDVI. Though the polar desert tundra area had the highest precipitation, its threshold value of the mean annual NDVI was only 0.0776 . This may be because the air temperature in the polar desert tundra area was very low, and the vegetation growth in this region was mainly limited by the temperature condition but not the water condition.

Table 1. Threshold value of mean annual NDVI and its response to precipitation change under water balance between 1982 and 2015 in different desert areas over the Silk Road Economic Belt.

\begin{tabular}{cccc}
\hline Desert Area Type & $\begin{array}{c}\text { Threshold Mean } \\
\text { Annual NDVI }\end{array}$ & $\begin{array}{c}\text { Mean Annual } \\
\text { Precipitation }\end{array}$ & $\begin{array}{c}\text { Mean Annual NDVI Change } \\
\text { with Precipitation Change }\end{array}$ \\
\hline Hot arid desert & $0.1041 \pm 0.0020$ & 83.62 & $0.0057 / 100 \mathrm{~mm}$ \\
Cold arid desert & $0.1337 \pm 0.0047$ & 169.39 & $0.0245 / 100 \mathrm{~mm}$ \\
Cold arid semi-desert & $0.1346 \pm 0.0046$ & 220.96 & $0.0350 / 100 \mathrm{~mm}$ \\
Hot arid desert semi-desert & $0.0951 \pm 0.0016$ & 86.76 & $0.0001 / 100 \mathrm{~mm}$ \\
Polar desert tundra & $0.0776 \pm 0.0047$ & 615.76 & $0.0037 / 100 \mathrm{~mm}$ \\
Hot arid desert shrub & $0.1071 \pm 0.0016$ & 66.70 & $0.0023 / 100 \mathrm{~mm}$ \\
Cold arid desert steppe & $0.1377 \pm 0.0051$ & 240.21 & $0.0247 / 100 \mathrm{~mm}$ \\
Polar desert steppe & $0.0701 \pm 0.0031$ & 406.04 & $0.0030 / 100 \mathrm{~mm}$ \\
\hline
\end{tabular}




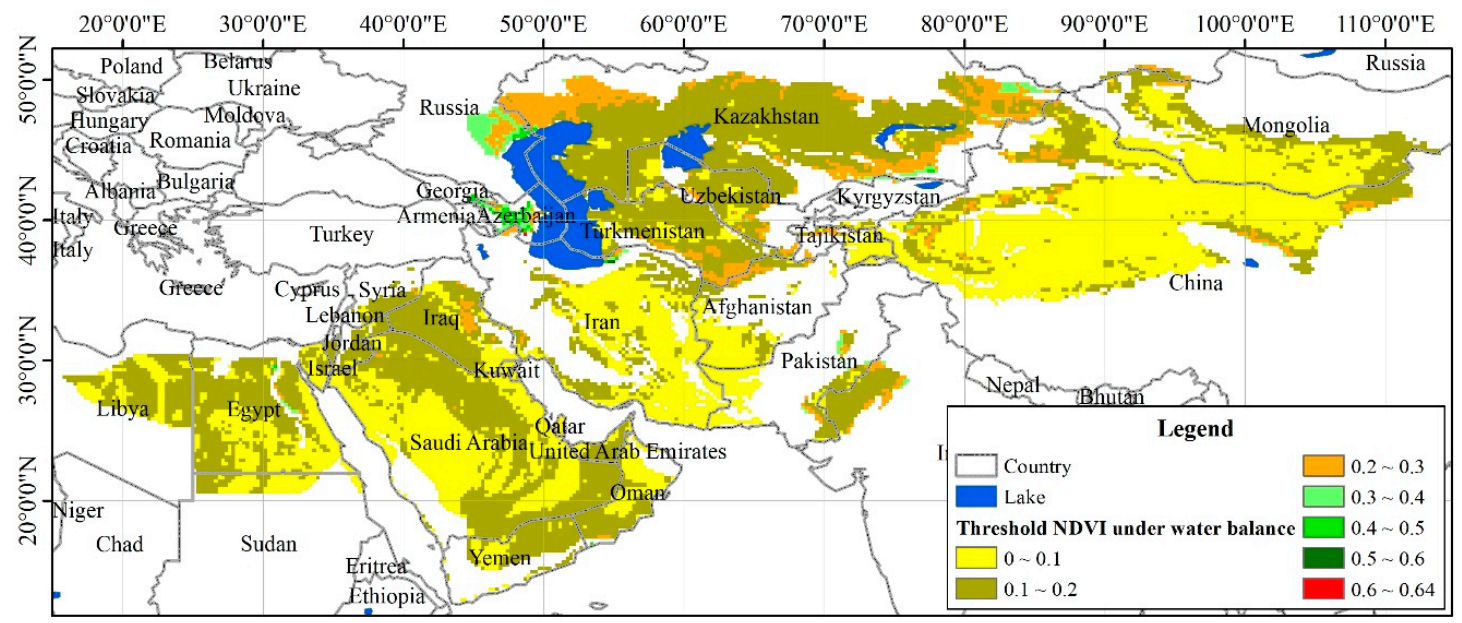

Figure 7. Threshold value of the mean annual NDVI under water balance between 1982 and 2015 over the Silk Road Economic Belt.

\section{Discussion}

\subsection{Different Change Patterns of Vegetation Growth}

Our results indicated remarkable spatial and temporal heterogeneity of vegetation growth in desert areas over the Silk Road Economic Belt. For the spatial pattern, both the high value and the pronounced change of the mean annual NDVI mainly appeared in the high-latitude region, especially in the cold arid desert area and cold arid semi-desert area in our study region. Jeganathan et al. demonstrated that high latitudes experienced the greatest changes in vegetation phenology [42] while de Beurs et al. also found the majority of land surface changes between 2001 and 2013 occurred in Kazakhstan and Uzbekistan [12]. For the temporal variation, we found an obvious turning point of the mean annual NDVI around 1994, which has been revealed by lots of previous studies, i.e., vegetation growth varied with a piecewise trend and the expansion of browning trends accelerated in 1990s [38,43,44]. Moreover, we found the browning region after 1994 was concentrated on the cold arid desert area, which was also consistent with Jeong et al., who declared that the vegetation growth decreased by $6.8 \%$ from 1998 to 2008 in the desert regions of Asia, and the bare soil areas inside the desert boundaries expanded by $8.7 \%$ per decade in the 2000s [45]. It should be noted that different remote sensing datasets often identify contrasting vegetation greenness trends [32,33], and extremely low NDVI values during the non-growing season may affect the calculation of the mean annual NDVI [46]; thus, more efforts are required to evaluate NDVI time series against field measurements of vegetation growth, primary productivity, and other biological processes in order to better understand ecosystem dynamics over the Silk Road Economic Belt.

\subsection{Integrated Effect of Environmental Factors on Vegetation Growth}

Among various climatic variables involving in vegetation-atmosphere interactions, precipitation variability is strongly related to vegetation change in arid and semi-arid regions due to the dominant role that it plays in water availability $[17,19]$. We found NDVI presented a strong positive relationship with both precipitation and evapotranspiration in most desert areas over the Silk Road Economic Belt. Moreover, both precipitation and soil water content decreased after 1994, while both air temperature and evapotranspiration increased in all desert areas after 1994. Therefore, water stress will be exacerbated, which may be one key reason for the "turning point" of the mean annual NDVI around 1994. Jeong et al. also revealed that increased precipitation in desert along $40^{\circ} \mathrm{N}$ provided favorable conditions for vegetation growth (i.e., greening) in the 1990s but reduced precipitation and intensified warming, causing less moisture to be available for vegetation growth (i.e., browning) in the 2000s [45]. 
Particularly important, the region of west Asia will likely experience more drought events with climate warming [13], and the coupling between vegetation growth and precipitation will be stronger with the enhancement of drought $[47,48]$. Moreover, it has been demonstrated that vegetation growth has a 1-3-month lag response to precipitation anomalies [17,19], and winter precipitation can be an important component of the plant water budget during the following warm season [49]. Our study also found a temporal lag between precipitation anomalies and vegetation activity of 2 months but no significant lag at the annual scale (not included in this paper). Except for climate change, the vital relevance of anthropogenic activities on vegetation degradation has been proven by plenty of studies $[9,12,45]$, indicating the necessity to combine climate change and human activities together for a deep understanding of the vegetation dynamics over the Silk Road Economic Belt.

\subsection{Threshold Vegetation Greenness and Its Response to Precipitation}

Determination of the water carrying capacity for vegetation could provide quantitative guidelines for the selection of plant species, density or biomass, and appropriate management for vegetative restoration [29]. Our study found that the threshold range of the mean annual NDVI was approximately 0.1153 0.1195 in the entire study region, and it was relatively higher in the cold arid areas, due to more precipitation. It is interesting that though the polar desert tundra had the maximum precipitation, the threshold NDVI was only about 0.0776 , owing to the high elevation and dominant control by temperature conditions [14]. Though the research for a sustainable maximum vegetation density is necessary in arid and semi-arid areas, the quantification is not easy since it requires insightful understanding of the interactions between vegetation growth and environment change. Previous studies about the water carrying capacity for vegetation were mainly based on empirical methods, conceptual models, and physical models at the local scale [24,26,29]; however, all of them were difficult to use over the Silk Road Economic Belt, due to the lack of field experiments and sufficient data. Consequently, we tried to estimate the water carrying capacity for vegetation using a statistical model based on a remote sensing-derived vegetation index and climatic factors. However, because of the high spatiotemporal variability of vegetation growth and environmental conditions, both the scale issues and the uncertainly estimation are essential in future studies using higher resolution data (e.g., site observation, MODIS, Landsat, etc.) [50].

\section{Conclusions}

This research sought to show the spatiotemporal variation of vegetation growth and its influence by climatic factors in different desert areas over the Silk Road Economic Belt. Both the mean value and interannual change of NDVI between 1982 and 2015 increased with the increase of the latitude. It showed dramatic greening from 1982 to 1994 in all desert areas, while significant browning after 1994 was concentrated on the cold arid desert area. The climate condition generally appeared as a warming and drying trend in the past 34 years, and was dominated by warming in the hot arid desert area, and hot arid desert semi-desert area, and by drying in the cold arid desert steppe area. NDVI presented a strong positive relationship with both precipitation and evapotranspiration in most desert areas. The threshold range of the mean annual NDVI under the water balance between 1982 and 2015 was approximately $0.1153 \sim 0.1954$ in the whole study region, and was the highest in the cold arid areas, followed by the hot arid areas and polar areas. The response of this threshold value to precipitation was all positive in different desert areas. These results provide an enhanced understanding of not only what areas are facing critical degradation under climate change and should be protected, but also what areas can be grazed by livestock more sustainably, or may support rainfed agriculture, which is critical for the regional eco-environmental management and sustainable socioeconomic development over the Silk Road Economic Belt.

Author Contributions: Conceptualization, Y.-J.M., X.H. and X.-Y.L.; methodology, Y.-J.M.; software, F.-Z.S.; validation, Y.-J.M.; formal analysis, Y.-J.M.; investigation, Y.-J.M. and F.-Z.S.; resources, F.-Z.S.; data curation, 
F.-Z.S.; writing—original draft preparation, Y.-J.M.; writing—review and editing, X.-Y.L. and X.H.; visualization, Y.-J.M. and F.-Z.S.; supervision, X.-Y.L.; project administration, X.H.; funding acquisition, X.H. All authors have read and agreed to the published version of the manuscript.

Funding: This research was funded by the National Key Research and Development Program of China (grant number: 2016YFE0203400-01) and the National Natural Science Foundation of China (grant number: 41771026, 41730854).

Conflicts of Interest: The authors declare no conflict of interest.

\section{References}

1. Duan, F.; Ji, Q.; Liu, B.Y.; Fan, Y. Energy investment risk assessment for nations along China's Belt \& Road Initiative. J. Clean. Prod. 2018, 170, 535-547.

2. Shi, K.F.; Yu, B.L.; Huang, C.; Wu, J.P.; Sun, X.F. Exploring spatiotemporal patterns of electric power consumption in countries along the Belt and Road. Energy 2018, 150, 847-859. [CrossRef]

3. Qi, X.Z.; Jia, J.H.; Liu, H.Y.; Lin, Z.S. Relative importance of climate change and human activities for vegetation changes on China's silk road economic belt over multiple timescales. Catena 2019, 180, $224-237$. [CrossRef]

4. Hu, Z.Y.; Zhou, Q.M.; Chen, X.; Qian, C.; Wang, S.S.; Li, J.F. Variations and changes of annual precipitation in Central Asia over the last century. Int. J. Climatiol. 2017, 37, 157-170. [CrossRef]

5. Haag, I.; Jones, P.D.; Samimi, C. Central Asia's changing climate: How temperature and precipitation have changed across time, space, and altitude. Climate 2019, 7, 123. [CrossRef]

6. Lioubimtseva, E.; Henebry, G.M. Climate and environmental change in arid Central Asia: Impacts, vulnerability, and adaptations. J. Arid Environ. 2009, 73, 963-977. [CrossRef]

7. Siegfried, T.; Bernauer, T.; Guiennet, R.; Sellars, S.; Robertson, A.W.; Mankin, J.; Bauer-Gottwein, P.; Yakovlev, A. Will climate change exacerbate water stress in Central Asia? Clim. Chang. 2012, 112, 881-899. [CrossRef]

8. Sorg, A.; Bolch, T.; Stoffel, M.; Solomina, O.; Beniston, M. Climate change impacts on glaciers and runoff in Tien Shan (Central Asia). Nat. Clim. Chang. 2012, 2, 725-731. [CrossRef]

9. Hilker, T.; Natsagdorj, E.; Waring, R.H.; Lyapustin, A.; Wang, Y.J. Satellite observed widespread decline in Mongolian grasslands largely due to overgrazing. Glob. Chang. Biol. 2014, 20, 418-428. [CrossRef] [PubMed]

10. Yang, Y.; Wang, Z.Q.; Li, J.L.; Gang, C.C.; Zhang, Y.Z.; Zhang, Y.; Odeh, I.; Qi, J.G. Comparative assessment of grassland degradation dynamics in response to climate variation and human activities in China, Mongolia, Pakistan and Uzbekistan from 2000 to 2013. J. Arid Environ. 2016, 135, 164-172. [CrossRef]

11. Xin, J.Y.; Gong, C.S.; Wang, S.G.; Wang, Y.S. Aerosol direct radiative forcing in desert and semi-desert regions of northwestern China. Atmos. Res. 2016, 171, 56-65. [CrossRef]

12. De Beurs, K.M.; Henebry, G.M.; Owsley, B.C.; Sokolik, I. Using multiple remote sensing perspectives to identify and attribute land surface dynamics in Central Asia 2001-2013. Remote Sens. Environ. 2015, 170, 48-61. [CrossRef]

13. Han, T.T.; Chen, H.P.; Hao, X.; Wang, H.J. Projected changes in temperature and precipitation extremes over the Silk Road Economic Belt regions by the Coupled Model Intercomparison Project Phase 5 multi-model ensembles. Int. J. Climatol. 2018, 38, 4077-4091. [CrossRef]

14. Nemani, R.R.; Keeling, C.D.; Hashimoto, H.; Jolly, W.M.; Piper, S.C.; Tucker, C.J.; Myneni, R.B.; Running, S.W. Climate-driven increases in global terrestrial net primary production from 1982 to 1999. Science 2003, 300, 1560-1563. [CrossRef]

15. Seddon, A.W.R.; Macias-Fauria, M.; Long, P.R.; Benz, D.; Willis, K.J. Sensitivity of global terrestrial ecosystems to climate variability. Nature 2016, 531, 229-232. [CrossRef] [PubMed]

16. Anyamba, A.; Tucker, C.J. Analysis of Sahelian vegetation dynamics using NOAA-AVHRR NDVI data from 1981-2003. J. Arid Environ. 2005, 63, 596-614. [CrossRef]

17. Gessner, U.; Naeimi, V.; Klein, I.; Kuenzer, C.; Klein, D.; Dech, S. The relationship between precipitation anomalies and satellite-derived vegetation activity in Central Asia. Glob. Planet. Chang. 2013, 110, 74-87. [CrossRef]

18. Propastin, P.A.; Kappas, M.; Muratova, N.R. Inter-annual changes in vegetation activities and their relationship to temperature and precipitation in Central Asia from 1982 to 2003 . J. Environ. Inform. 2008, 12, 75-87. [CrossRef] 
19. Chen, Z.F.; Wang, W.G.; Fu, J.Y. Vegetation response to precipitation anomalies under different climatic and biogeographical conditions in China. Sci. Rep. UK 2020, 10, 830. [CrossRef]

20. Xu, S.Q.; Yu, Z.B.; Yang, C.G.; Ji, X.B.; Zhang, K. Trends in evapotranspiration and their responses to climate change and vegetation greening over the upper reaches of the Yellow River Basin. Agr. For. Meteorol. 2018, 263, 118-129. [CrossRef]

21. Ning, T.T.; Zhou, S.; Chang, F.Y.; Shen, H.; Li, Z.; Liu, W.Z. Interaction of vegetation, climate and topography on evapotranspiration modelling at different time scales within the Budyko framework. Agr. For. Meteorol. 2019, 275, 59-68. [CrossRef]

22. Du, T.; Wang, L.; Yuan, G.F.; Sun, X.M.; Wang, S.S. Effects of distinguishing vegetation types on the estimates of remotely sensed evapotranspiration in arid regions. Remote Sens. Basel 2019, 11, 2856. [CrossRef]

23. Guo, Z.S.; Shao, M.A. Mathematical model for determining vegetation carrying capacity of soil water. J. Hydraul. Eng. 2004, 35, 95-99.

24. Xia, Y.Q.; Shao, M.A. Soil water carrying capacity for vegetation: A hydrologic and biogeochemical process model solution. Ecol. Model. 2008, 214, 112-124. [CrossRef]

25. Xia, Y.Q.; Shao, M.A. Evaluation of soil water-carrying capacity for vegetation: The concept and the model. Acta Agr. Scand. B Soil Plant Sci. 2009, 59, 342-348. [CrossRef]

26. Liu, J.L.; Wang, Y.H.; Yu, P.T.; Cheng, L.L.; Xiong, W.; Xu, L.H.; Du, A.P. Vegetation carrying capacity based on soil water on typical slopes in the Diediegou small watershed of Liupan Mountains. Chin. J. Plant Ecol. 2009, 33, 1101-1111.

27. Wang, N.; Bi, H.X.; Guo, M.X.; Kong, L.X.; Hou, G.R.; Chang, Y.F. Study on soil water vegetation carrying capacity of Robinia pseudoacacia Plantation in the loess gully area of western Shanxi Province. J. Soil Water Conserv. 2019, 33, 213-219.

28. Tian, Y.L.; He, Y.H.; Guo, L.S. Soil water carrying capacity of vegetation in the northeast of Ulan Buh Desert. Sci. Silvae Sin. 2008, 44, 13-19. [CrossRef]

29. Liu, B.X.; Shao, M.A. Modeling soil-water dynamics and soil-water carrying capacity for vegetation on the Loess Plateau, China. Agr. Water Manag. 2015, 159, 176-184. [CrossRef]

30. Zhang, J.T.; Zhang, Y.Q.; Qin, S.G.; Wu, B.; Ding, G.D.; Wu, X.Q.; Gao, Y.; Zhu, Y.K. Carrying capacity for vegetation across northern China drylands. Sci. Total Environ. 2020, 710, 136391. [CrossRef]

31. Tucker, C.J.; Pinzon, J.E.; Brown, M.E.; Slayback, D.A.; Pak, E.W.; Mahoney, R.; Vermote, E.F.; El Saleous, N. An extended AVHRR 8-km NDVI dataset compatible with MODIS and SPOT vegetation NDVI data. Int. J. Remote Sens. 2005, 26, 4485-4498. [CrossRef]

32. Alcaraz-Segura, D.; Chuvieco, E.; Epstein, H.E.; Kasischke, E.S.; Trishchenko, A. Debating the greening vs. browning of the North American boreal forest: Differences between satellite datasets. Glob. Chang. Biol. 2010, 16, 760-770. [CrossRef]

33. Guay, K.C.; Beck, P.S.A.; Berner, L.T.; Goetz, S.J.; Baccini, A.; Buermann, W. Vegetation productivity patterns at high northern latitudes: A multi-sensor satellite data assessment. Glob. Chang. Biol. 2014, 20, 3147-3158. [CrossRef] [PubMed]

34. Cornes, R.C.; Schrier, G.V.D.; Squintu, A.A. A reappraisal of the thermal growing season length across Europe. Int. J. Climatol. 2019, 39, 1787-1795. [CrossRef]

35. Betts, A.K.; Chan, D.Z.; Desjardins, R.L. Near-surface biases in ERA5 over the Canadian prairies. Front. Environ. Sci. 2019, 7, 129. [CrossRef]

36. Miralles, D.G.; Holmes, T.R.H.; de Jeu, R.A.M.; Gash, J.H.; Meesters, A.G.C.A.; Dolman, A.J. Global land-surface evaporation estimated from satellite-based observations. Hydrol. Earth Syst. Sci. 2011, 15, 453-469. [CrossRef]

37. Martens, B.; Miralles, D.G.; Lievens, H.; van der Schalie, R.; de Jeu, R.A.M.; Fernández-Prieto, D.; Beck, H.E.; Dorigo, W.A.; Verhoest, N.E.C. GLEAM v3: Satellite-based land evaporation and root-zone soil moisture. Geosci. Model Dev. 2017, 10, 1903-1925. [CrossRef]

38. Pan, N.Q.; Feng, X.M.; Fu, B.J.; Wang, S.; Jie, F.; Pan, S.F. Increasing global vegetation browning hidden in overall vegetation greening: Insights from time-varying trends. Remote Sens. Environ. 2018, 214, 59-72. [CrossRef]

39. Byrne, B.M. Structural Equation Modeling with Mplus: Basic Concepts, Applications, and Programming; Routledge: New York, NY, USA, 2013; pp. 3-17. 
40. Grace, J.B.; Schoolmaster, D.R.; Guntenspergen, G.R.; Little, A.M.; Mitchell, B.R.; Miller, K.M.; Schweiger, E.W. Guidelines for a graph-theoretic implementation of structural equation modeling. Ecosphere 2012, 3. [CrossRef]

41. Dinc, M.; Duman, A.; Tufekcioglu, M.; Tufekcioglu, A. Biomass allocation in relation to precipitation, temperature and soil properties in the grassland of Coruh River Basin, Turkey: Using structural equation modelling with Amos. Int. J. Ecosyst. Ecol. Sci. 2018, 8, 457-470. [CrossRef]

42. Jeganathan, C.; Dash, J.; Atkinson, P.M. Remotely sensed trends in the phenology of northern high latitude terrestrial vegetation, controlling for land cover change and vegetation type. Remote Sens. Environ. 2014, 143, 154-170. [CrossRef]

43. Jong, R.D.; Verbesselt, J.; Schaepman, M.E.; Bruin, S.D. Trend changes in global greening and browning: Contribution of short-term trends to longer-term change. Glob. Chang. Biol. 2012, 18, 642-655. [CrossRef]

44. Piao, S.L.; Wang, X.H.; Ciais, P.; Zhu, B.; Wang, T.; Liu, J. Changes in satellite-derived vegetation growth trend in temperate and boreal Eurasia from 1982 to 2006. Glob. Chang. Biol. 2011, 17, 3228-3239. [CrossRef]

45. Jeong, S.J.; Ho, C.H.; Brown, M.E.; Kug, J.S.; Piao, S.L. Browning in desert boundaries in Asia in recent decades. J. Geophys. Res. 2011, 116, D02103. [CrossRef]

46. Jia, G.J.; Epstein, H.E.; Walker, D.A. Spatial heterogeneity of tundra vegetation response to recent temperature changes. Glob. Chang. Biol. 2006, 12, 42-55. [CrossRef]

47. Liu, H.Y.; Piao, S.L. Drought threatened semi-arid ecosystems in the Inner Asia. Agr. For. Meteorol. 2013, 178-179, 1-2. [CrossRef]

48. Xu, H.J.; Wang, X.P.; Zhang, X.X. Decreased vegetation growth in response to summer drought in Central Asia from 2000 to 2012. Int. J. Appl. Earth Obs. 2016, 52, 390-402. [CrossRef]

49. Nagler, P.L.; Glenn, E.P.; Kim, H.; Emmerich, W.; Scott, R.L.; Huxman, T.E.; Huete, A.R. Relationship between evapotranspiration and precipitation pulses in a semiarid rangeland estimated by moisture flux towers and MODIS vegetation indices. J. Arid Environ. 2007, 70, 443-462. [CrossRef]

50. Guerschman, J.P.; Van Dijk, A.I.J.M.; Mattersdorf, G.; Beringer, J.; Hutley, L.B.; Leuning, R.; Pipunic, R.C.; Sherman, B.S. Scaling of potential evapotranspiration with MODIS data reproduces flux observations and catchment water balance observations across Australia. J. Hydrol. 2009, 369, 107-119. [CrossRef] 